$$
\text { NASA TH } X>0.594
$$

\title{
OCEAN COLOR SPECTRUM CALCULATIONS
}

\section{W. R. MCCLUNEY}

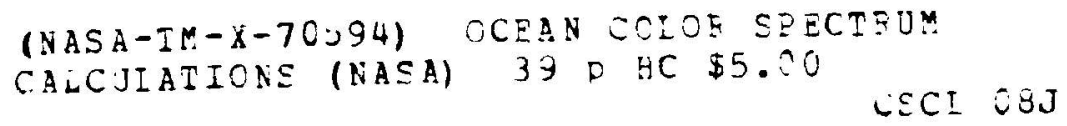

FEBRUAAY 1974 
For information concerning availability of this document contact:

Technical Information Division, Code 250

Goddard Space Flight Center

Greenbelt, Maryland 20771

(Telephone 301-982-4488) 
OCEAN COLOR SPECTRUM CALCULATIONS

W. R. McCluney

Hydrology and Oceanography Branch

NASA/Goddard Space Flight Center

February 1974

GODDARD SPACE FLIGHT CENTER

Greenbelt, Maryland 


\title{
OCEAN COLOR SPECTRUM CALCULATIONS
}

\author{
W. R. McCluney \\ NASA/Goddard Space Flight Center \\ Code 913
}

Greenbelt, Maryland 2077 !

\begin{abstract}
There is obvious value in developing the means for measuring a number of subsurface oceanographic parameters using remotely sensed ocean color data. The first step in this effort should be the development of adequate theoretical models relating the desired oceanographic parameters to the upwelling radiances to be observed. A portion of a contributory theoretical model can be described by a modified single scattering approach based upon a simple treatment of multiple scattering. The resulting quasi-single scattering model can be used to predict the upwelling distribution of spectral radiance emerging from the sea. The shape of the radiance spectrum predicted by this model for clear ocean water shows encouraging agreement with measurements made at the edge of the Sargasso Sea off Cape Hatteris.
\end{abstract}




\section{OCEAN COLOR SPECTRUM CALCULATIONS}

\section{INTRODUCTION}

A. large number of techniques have be en developed for sampling the ocean from top to bottom. But horizontal sampling of the ocean has been conducted on a reasonable scale only rarely, and then only at considerate expense of time and money. It is true that a suitably equipped research vessel can cover large areas of the ocean and collect a large amount of data in a single cruise. However, with the relatively small cruising speeds available today, the areai extent over which the meas' rements can be assumed to be synoptic is severely limited.

As the field of oceanography becomes more and more sophisticated, with many scientists actively involved in large-scale modeling of oceanographic parameters, the need ior synoptic data will continue to increase. But until the number of available suitably equipped research vessels increases several orders of magnitude and their maximum speeds increase very substantially, neither of which is very likely to happen in the near future, we will need to rely on data collected by aircraft and satellites in order to obtain the kind of large-scale synoptic data that is needed to bulld accurate mociels suitable for prcuirtion. The need for synoptic data on the ocean, and especially the near-shore areas, is so great that much effort should be expended in this decade aimed at obtaining this data by remote sensing, both actively and passively from aircraft and satellites.

Due to the essentially opaque nature of seawater outside the visible and near ultra-violet portions of the electromagnetic spectrum, remote measurements of subsurface oceanographic parameters will necessarily be limited to 
these spectral regions. By "subsurface" is here meant the region from a few millimeters to a few tens of meters depth, the region of penetration of sunlight and skylight into she sea. Until the maximum weight and power limitations imposed on present-day scientific satellites is permitted to expand significantly, most of the subsurface information collected fro'n spacecraft will necessarily pe limited to the passive mode, wherein one monitors the incoming radiation from the sun and sky scattered upward at subsurface depths.

Of the many subsurface oceanographic parameters of interest to oceanugraphers, only a few can be expected to have a significant influence on the observed vcean color spectrum.

In deep water areas the most obvious of these parameters are:

(1) Total particulate concertration.

(2) Concentration of organic particulates (mostly phytoplankton).

(3) Concentration of inorganic particulates (mostly silicas and other sediments).

(4) Average particulate index of refraction.

(5) Tonccutrations of various pigments such as chlorophy and the carotenoids found in phytoplankton.

(6) Concentration and composition of dissolved substances.

(7) Parameters related to the shape and/or magnitude of the particle size distribution curve.

(8) Surface front iocation (frequently delineated by foam lines on the surface and by subtle changes in ocear. color ${ }^{1}$ ). 
In addition, for shallow water areas of sufficient clarity, it should be possible to determine the extent of bottom vegetation and other bottom parameters.

By coupling ocean col or data with sea surface temperature data it has been shown to be feasible to identify coastal and deep water upwellings and to map major ocean currents. ${ }^{2}$ The loop current in the Gulf of Mexico and the Gulf stream, with its meanders in the North Atlantic, are two prominent examples.

Althougi much work has been done in analyzing ocean color data gathered by a variety of sensors, including the nultispectral scanner on NASA's ERTS-1 satellite, much of this analysis has been purely qualitation in nature. It is not yet clear which subsurface oceanographic parame: rs we car measure from space $u$ ith acceptable accuracy on a quantitative basis. An experimentai and theoretical effort is needed in order to identify these parameters, the measurement accurasies which can be expected for each one, and to develop the analysis techniques suitable for use with remotely sensed ocean color data.

There are two different approaches to the data analysis problem which can be taken. The first involves the measureinent of optically important subsurface parameters together with the corresponding ocean color spectrum at a large number of different locations in the sea. Multivariate statistical analyses can th $2 n$ be applied to this data in order to identify correlations between variations in the subsurface parameters and $c$ rres; onding changes in the ocean color specirum.

In the second approach, the optical processes taking place in the ocean are modeled mathematically so that the ocean color spectrum can be directly related to the optically important subsurface parameters which influence it. Once this 
model has been developed and verified, it can be used to simulate a great variety of remote measurement situations with a considerable savings of time and money. Furthermore, it can then be extended with somewhat greater confidence to measurement situations not encountered in the model-development stage of the program.

The statistical approacn to this problem has been discussed by Mueller. ${ }^{3}$ The remainder of this paper will be concerned with the theoretical modeling approach .

\section{REMOTE SENSING OF OCEAN COLOR}

Figure 1 illustrates the optical processes involved with satellite ocean color measurements. The upwelling radiance just below the sea surface is made up of sun and sky light which has been multiply scattered, with spectrally selective absorption and scattering by both the molerular anci particuiate components in the sea water contributing to the shape of the upwelling radiance spectrum. Thus, the wavelength spectrum of this upwelling light will depend upon the amount and kinds of dissolved and particulate substances in the water.

The light received by a high altitude sensor is composed of light emerging from the sea, path radiance produced by the atmosphere, and sun and sky light specularly (and diffusely in the presence of whitecaps) reflected from the surface of the sea. In clear deep water areas, viewed from a high altitude, the light emerging from the sea is a relatively small purtion of the total light received by the sensor.

Recent . surements by Hovis ${ }^{4}$ (reproduced in Figure 2) have shown that the observed radiance at high altitude can be as much as five times that at low 
altitude. This points up the necessity to account for the effects of atmospheric path radiance and sea surface reflection in any high altitude ocean color data analysis program. It is also important to choose sun and look angles at the time of the measurement so as to minimize the effects of sun glitter.

Fortunately, considerable effort has already been puccessfully expended in the development of radiative transfer models of the atmosphere applicable to remote sensing problems..$^{5-8}$ Several years ago Cox and Munk developed a model for treating the specular reflection of sunlight from the sea surface.? Strong and Ruff have demonstrated the application of Cox and Munk statistics to satellite observations. ${ }^{10}$ Thus, only the subsurface portion of the overall radiation transfer model remains to be developed in detai?.

\section{AN OPTICAL MODEL FOR OCEAN COLOR}

A full-scale sinulation of the optical processes involved in the remote sensing of ocean color is desired. The subsurface portion of this simulation can be conveniently divided into two components, the microscopic and the macroscopic, as shown in Figure 3.

With the microscopic model, the concentrations and particle size distributions of dissolved and particulate matter are assumed known. If the spectral absorption and suattering properties of these substances are also known the bulk absorption and scattering of the medium can be determined by straightforward procedures. Andre Morel has made considerable progr $\epsilon_{\overline{5}} \mathrm{~s}$ in describing the absorption and scattering properties of pure seawater. ${ }^{11}$ Adding the spectral absorption of dissolved materials (called yellow substance or gelbstoff) is not difficult, if the specinic absorption spectra and concentrations of these materials 
are kno:vn. In his book on optical oceainography, ${ }^{12}$ Jerlov gives an absorption curve for yellow substance but unfortunately the concentration corresponding to this curve is not given. Much work remains to be done in identifying the component materials present in yellow substance, determining their origins, measuring their absorption spectra, and in developing better techniques for accurately measuring their concentrations.

The particulates contained in seawater present a fundamentally more difficult problem. Although Lorenz, Mie, and DeBye developed an excellent theory for the scattering of light by homogeneous spherical particles ${ }^{13}$ (extended by Kerker to include layered spheres ${ }^{14}$ ), the major scattering particles in the sea are highly aspheric and in general inhomogeneous in refractive index and the Lor $\in$ z-Mie theory is not applicable. (In certain circumstances it may be applied to gain useful information about the nature of the scattering processes, but it is not generally applicable.) As a result, much theoretical and experimental work must be done in this area before an accurate, workable inicroscopic model can be developed whicil is capable of generating the spectral extinction and scattering properties of seawater cver the full visible range. Once such a model has been developed, thi: information which it provides can be used as i.plit data for the second portion of the subsurface optical model which is described next.

The macroscopic optical model takes the extinction and scattering properties of the medium (either theoretically or experimentally determined), together vith the incident spectral irradiance of sunlight and skylight, the sea surface roughness, and information about the spectral albedo of the bottom (if the water is shallow) and predicts the upwelling spectral radiance emerging from the sed. The macroscupic model is based on radiative transfer theory and should incit i. 
the effects of multiple scattering within the sea. Gordon and Brown have systematically applied a Monte-Carlo radiative transfer model to the ocean color problem. ${ }^{15}$ With the addition of a diffusely reflecting bottun to their model ${ }^{16}$ they have been able to obtain good agreement with some early measurerents of the ocean color spectrum in shallow water made by Duitley. ${ }^{17}$

An advantage of their model is that it ises realistic, measured sca:tering functions and makes no special assumptions as to the shape of those functions. A disadvantage, as with all Monte Carlo models, is that wiile it produces accuratc upwelling irradiances entering a fu:l $2 \tau$ sterradians, the calcuiation of upwelling radiances over narrow angular ranges requires considerably more computation time for the desired accuracies. We shall see later, however, that this is not a serious shartcoming.

An accurate radiative transfer solution, such as the one developed by Gordon and Brown will be needed for proper interpretation of remotely sensed ocean color data. For certain applications, as in remote senscr design studies, a simpler, approximate model may be adequate. Jerlov has discussed such a mode $1^{12}$ which he used to determine the angular dependence of upwelling ridiance at a single wavelength. It is a single-scattering theory for the sun-on!y case and for an infinitely deep ocean having a perfectly flat upper surface. This paper provides an extension of this model to include incident skylight and the spectral as well as the angular variation in upwelling radiance emerging from the sea. A detailed derivation of the ujwelling spectral radiance equations is given in the Appendix.

Gordon has suggested a simple modification to the resulting equations which approximately considers the effects of multiple scattering in the sun-only case..$^{18}$ 
As will be shown in the next section, in certain cases this modified model gives very good agreement with the Monte-Carlo calculations of Gordon ani Brown for both the sun-only and the sky-only cases as well. The derivation of the modified single-scattering model is cutlined in the Appendix. Some results of its use in the calculation of ocean color spectra will be giv $\urcorner n$ in a later section.

\section{VERIFICATION OF THE QUASI-SINGLE SCATTERING MODEL}

Due to the strong forward scattering found in natural waters, a relatively simple assumption may be used in order to modify the single scattering model to partially account for the effects of multiple scattering. This mudification is described in the Appendix.

Equations 14 and 15 in the Appendix give the results for a homogeneous. infinitely deep ocean. In order to test their validity the radiances given by these equations were numerically integrateu over $2 \pi$ sterradians to give the total upwelling irradiances due to sun and sky emerging from the sea. These irradiances were then divided by the correspording downwelling incident irradiances to obtain irradiance reflectances for comparison with the results of the Gordon and Brown Monte-Carlo multiple scattering calculations given in reference 13 .

In order to describe this comparison we must define some terms. The scattering phase function $\mathbf{P}$ is defined to be $\beta / \mathrm{b}$, where $\beta$ is the volume scattering function and $b$ is the total scattering coefficient. Both arc defined in the Appendix. The scattering albedo $\omega_{0}$ is defined to be the ratio $-f$ is to $c$, where $c$ is the extirction coefficient (labelled a by many authors).

Three scattering phase iunctions, designated A, B, and $\triangle$ typical for the Srrgasso Sei, 'vere used hy Gordon and Brown for their caleulatiuns. 'I' te 
irradiance reflectivity is plotted in Figures 4,5 and 6 as a function of $\omega_{0}$ for each of these phase functions. The predictions of the sirgle scattering (SS), quasi-single scatering (QSS), and multiple scattering (MS) mocicls are shown for both the sun-only and sky-only cases in each Figure.

There is a substantial difference between the single scatiering and multiple scattering models for values of $\omega_{0}$ greater than about 0.3 . But with the quasisingle scattering model, as can be seen clearly in Figures 4 through 6 , yood $a_{\xi}$ reement with the MS model is maintained up to an $\omega_{0}$ of about 9.85 . The difference between sun-only and sky-only cases is less than $1 \%$ for all values of $\omega_{0}$ used.

These results indicate the importance of the shape of the scattering functi' $n$ in remote sensing, for one can conceivabiy have substaritially different reflectances for two different phase functions even though ${ }^{\omega_{0}}$ might be the same in both cases. Since the upweiiing rudiance is strongly dependent on the shape of the scattering function, this dependence must not be overlooked.

A plot of the variation of $\omega_{0}$ with wavelength for clear water similar to that fourd in the Sargasso Sea is shown in Figlire 7 for reference. The Sargasso Sea a relatively homogeneous, somewhat stable body of very slear water havirg optical properties which remain quite constant with time. As such it affords a basis for comparison of different models. Even in the clearest of natural waters, scattering from particulates, mostly phytoplankton, predominates over molecular scattering, except in the case of blue light at large scattering angles where molecular and particulate scattering are roughl:" combarable. The data for

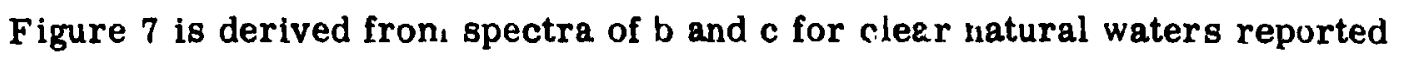
by Tyler, Smith, and Wilson. ${ }^{19}$ We can see that. $\omega_{0}$ ranģes frorn zero to 0.63 
over this spectrum. The agreement between the MS and the QSS models is quite goud as shown in Figures $4, \overline{3}$, and 6 for both sun and skylight cases over this range. In more turbid water one can expect somewhat higher peak values of $\omega_{0}$. In suct cases and for the limited reg:ons of the spectrum over which this occurs the accuracy of the QSS model may be limited. However, for the purposes to which the QSS model is intended, this limitation is rot overly confining.

A more serious limitation is that the agreement shown in Figures 4 through 6 applies only to calculations of upwelling irradiance. A remote sensor eceives upwelling radiance from a much smaller solid angle than the $2 \pi$ steradians used in these computations. A better test of the validity of the ass model would be $t$, compare QSS and MS calculations of upwelling radiance rather than irradiance. Unfortunately, however. the Gordon-and-Brown-comput 3 d radiances are probably not accurate enough for a meaningful somparison. To obtain some infor mation as to the errors which might result from this, the QSS model can be evaluated at several different look angles. When this is done using data representative of clear ocean water, as in the next section, and when the results are normalized at $520 \mathrm{~nm}$ and coinpared, it is found that the shape of the predicted spectrum is indepercicint of look angle ovt, the range from zero to 60 degrees.

Although this is not a prec: se test of the hypothesis that the QSS model is as good for predicting rawance spectra as it has beell silown to be for irradiance spectra, it should be sufficiently vaild for calculations not requiring high accu-racy. In any event, the QSS model should be much better than the SS model for these caiculations. Further proof will have to await more accurate calculations of upwelling radiance. 


\section{OCEAN COLOR SPECTRUM CALCULATIONS}

Before proceeding to use the QSS model equations (14 and 15 in the Appendix) for ocean color spectrum calculations, we shall examine them for any general implications which they might have for the remote sensing problem. We begin by writing these equations in terms of the phase function $P$ and scattering albedo $\%_{0}$ defined earlier, and divide them by the incident irradiances to get Sun-Only Case

$$
\frac{\mathbf{N}_{0}^{0}(\lambda)}{H_{0}(\lambda)}=K_{0} \frac{\omega_{0}(\lambda) P(\lambda)}{1-\omega_{0}(\lambda) \mathbf{F}(\lambda)}
$$

Sky-Only Case

$\frac{\mathrm{N}_{\mathrm{a}}^{\mathrm{s}}(\lambda)}{\mathrm{H}_{\mathrm{s}}(\lambda)}=\mathrm{K}_{\mathrm{s}}\left[\frac{\omega_{0}(\lambda)}{1-\omega_{0}(\lambda) \mathrm{F}(\lambda)}\right] \int_{0}^{2 \pi} \int_{180}^{\theta_{w}^{\mathrm{c}}} \frac{\mathrm{T}\left(\theta_{\mathrm{a}}^{\prime}\right) \mathrm{P}\left(\lambda, \dot{w}_{w}, \phi_{w}, \phi_{w}^{\prime}\right) \sin \theta_{w}^{\prime} \mathrm{d} \theta_{w}^{\prime} \mathrm{d} \phi_{w}^{\prime}}{\sec \theta_{w}-\sec \theta_{w}^{\prime}}$

$K_{0}$ and $K_{s}$ are wavelength-independent quantit $t_{1}$. All remaining previously undefined symbols are defined in the Appendix. The "radiance reflectances" given by these equations contain the predicted spectral variation in the ocean color spectrum attributable to properties of the sea alone.

For the moment, let us make an oversimplification, by assuming that the phase function $P(\lambda)$ (and hence the forward scattering coefficient $F(i)$ ) is not strongly wavilength dependent. In this case much of the spectral variation in the radiance reflectance would be due to spectral variations in $\omega_{0}$. If this were strictly true, the single-scattering albedo $\omega_{0}$ would therefore be the predominant contributor to the observed upwelling ocean color spectrum. On a clear day the irradiance incident on the surface will appear white to a visual observer. This 
leads to the conclusion that the ocean is blue mainly because the scattering albedo peaks in the blue portion of the spectrum. However, for accurate predictions of the upwelling radiance spectrum emerging from the sea we cannot igaore the spectral variations in the shape of the scattering phase function which are, in fact, substantial.

Thus we see clearly the point made by Gordon and Brown in reference 15, that for a given phase function all that $\mathrm{c}$ เn be determined about the medium from remote observations is $\omega_{0}$. Variations in the spectral distribution of upwelling radiance can be caused by $i_{0}(\lambda)$ and $P(\lambda, \vec{A})$ (or equivalently, by $c(\lambda)$ and $[i(\lambda, \hat{\theta}))$. If $\omega_{0}$ and $\mathbf{P}$ (or $\mathbf{c}$ and $\beta$ ) are independent variables in the sea, then it may not be possible to unambiguous!y determine them separately from a single measurement of the upwelling radiance spectrum.

As developed in the Appendix, the QSS model makes no assumptions about the shape of the scattering function or its wavelength dependence, other than that the function is strongly peaked in the forward direction. Let us now use this model to calculate a hypothetical upwelling radiance spectrum for clear natural water such as that found in the Sargasso Sea. As input data we shail usc tise c (i) spectrum given in reference 19 , a set of wavelength-dependent scattering functions based upon measurements oy Kullenberg in the Sargasso Sea ${ }^{20}$, and incident irradiances predicted by an atmospheric model for clear atm spheres developed by Curran. ${ }^{21}$ To obtain the wavelength dependent scattering functions, the scatteri' $g$ data of Kullenberg at 460 and $655 \mathrm{~nm}$ was linearly inter polated to give values for $3(X, 6)$ at $450,500,550,600$, and $650 \mathrm{~nm}$. In addition the function at 350 and $400 \mathrm{~nm}$ was set equal to that at $450 \mathrm{~nm}$ and at $700 \mathrm{~nm}$ it was set equal to 
that $a \pm 650 \mathrm{~nm}$. This is an admitiedly crude approximation of the wavelengthdependence of the scattering function. But accurate measurements of at more than two or three wavelengths at a time have not yet been made.

The input data which was used roughly approximates the situation for the Sargasso Sea on a cloudless, clear day. The resulting upweliing radiance spectra predicted by the SS and the QSS models for a zenith sun and nadir viewing are shown in Figure 8. These results show clearly the aifect of multirle scattering on the shape of the radianr. spectrum. The slight shift of the peak wavelength toward the blue when skylight $i$ added to the sun-only case is evident in this Figure.

In Figure 9 is shown a comparison of these tneoretical results (for a $60^{\circ}$ solar zenith angle) with the experimental results obtained by Hovis late in the afternoon on July 17, 1972 at an altitude of 305 meters at the edge of the Sargasso Sea (a distance of about $250 \mathrm{~km}$ N.E. of Cape Hatteras). ${ }^{22}$ The water is quite clear in this region and should not be much different from that found in the middle of the Sargasso Sea. Specular reflection of skylight and a small amount of sunglint are present in the Hovis data which are not accounted for in a tinecretica! caicuiditions. Aiso shown in Figure 9 is a normalized version of the experimental data drawn in order to compare the shape: of tir two spectra. Although the theoretical and exper imental data represent diffe.ent locations and tir.zes, it is encouraging that the shapes of the two spectra are similar.

The ratic of the experimental curve to the theoretical curve shown in Figure 9 (the normalization iactor) is approximately 3.3. Although this ratio is for the upweling radiance, it agrees in a very general way with measurements of 
upwelling irradiances made by F. J. Davis in 1941 at the surface of a deep, v'ind-rougi. ned fresh-water lake. ${ }^{23}$ For a solar zenith angle of $60^{\circ}$, Davis detyrmined that the total upwelling irradiance, due to reflected sun and skylight, Jlus that due to upwelling subsuriace light, was approximately 7.4 percent of the total incident light, integrated over the visible spectrum. The subsurface component was 2.5 percent of the total. Thus, the total upwelling irradiance was approximately three times the subsurface component. Although this is not in general likely to be true at all wavelengths in the visible, the Davis results tend to support the results shown in Figure 9 and lend further support for the validity of the QSS model in predictions of upwelling radiance spectra.

\section{CONCLUSIONS}

It is conclude $J$ thac the quasi-single scattering model gives a reasonably accurace estimate of upwelling radianne spentra annlicable to ocean color remote sensor design studies and for the development of ocean color data analysis techniques. The main advantage of the model lies in its simplicity. This permits calculations of :adiance spectra with only a few seconds of computer CPU time. A single program can run five sun angles, ten look angles, and b0 wavelengths in just a tew minutes of CPU time. All that is needed is accurate scattering and ext.inction data. This data may either be provided by experimental measuremenis Jr may be th: prodictions of a suitably formulated microsccpi model based upon ass umed or sasured concentrations of dissol vea and particulate matter in the sea.

Although the ocean color spectrur. predictions shown in Figure 9 were made or ly for clear, open r cean water, the agreement shown in 1 'gur 3845 , and 6 
over a wide range of $\omega_{0}$ insures that the accuracy of the model will be just as good in turtid water. This conclusion is further supported by the fact that the volume scattering function becomes even more strongly peaked in the fo: ward direction with increasing water turbidity, making the quasi-single scattering approximation even more valid than it is for clear water.

By cxtending the model to inciude the effects of reflection from a shallow bottom, transmission and reflection of sun and sky light from a rough upper surface and atmospheric path radiance, reasonably accurate predictions of the total upwelling radiance spectrum at high altitudes in or above the atmosphere should be possible.

The need for accurate measurements of the full spectral variations of the extinction coefficient and the volume scattering function should be obvious. These measurements are needed to provide realistic input data for the macroscopic model and to assist in the development of an accurate, useful microscopic model.

\section{ACKNOWLEDGEMENTS}

The author would like to acknowledge many helpful discussions with $H$. R. Gordon and O. B. Brown of the University of Miami, and Gary Wolford of Goddzrd Space Flight Center fur developing the coniputer code used to calculate Ss and QSS model radiance and irradiance spectra. 


\section{APPENDLX \\ DERIVATION OF THE QUASI-SINGLE SCATTERING \\ MACROSCOPIC OCEAN MODEL}

Consider the small element of volume $\mathrm{dV}=\mathrm{dAdz}$ of the scattering medium shown in Figure 10. Let $d F_{0}\left(\hat{\xi}^{\prime}\right)$ be the element of incident flux within the element of solid angle $\mathrm{d} \Omega\left(\hat{\xi}^{\prime}\right)$ prorngating in the direction specified by the unit vector $\hat{\xi}^{\prime}$. Let $d^{3} F_{s}\left(\hat{\xi}^{\prime}, \hat{\xi}\right)$ be the element of flux scattered from solid angle $\mathrm{d} \Omega\left(\hat{\xi}^{\prime}\right)$ into solid angle d $\Omega(\hat{\xi})$. The volume scattering function $q$, assumed constant uver $d V$, is defined by the relation

$$
\beta\left(z, \hat{\xi}^{\prime}, \hat{\xi}^{\prime}\right)=\frac{d^{3} F_{s}\left(z, \hat{\xi}^{\prime}, \hat{\xi}\right)}{H_{\text {in }}(z) d \Omega(\hat{\xi}) d A d z}
$$

where

$$
H_{\text {in }}(z)=\frac{d F_{0}\left(z, \hat{\xi}^{\prime}\right)}{d A^{\prime}}
$$

is the incider irradiance.

Let $\phi_{\text {w }}$ ani $\phi_{\mathrm{w}}$ be the priar ang? respect to the zenith. Lei $\phi_{a}$ a.d $\phi_{a}$ be the corresponding argles in air. Asr.uming a per iectly flat ccean, $\phi_{a}=\phi_{w}$ and $\sin \theta_{a}=\eta \sin \theta_{w}$, where $\eta_{j}$ is the index of refractic $n$ of seawater.

Using equation (3) we can write the following expressior for the element of upwelling radiance at depth $z$ due to a layer of thickness $\mathrm{dz}$, if ${ }^{\prime} J_{0}\left(z, \theta^{\prime}, \phi^{\prime}\right)$ is the angular ristribution of downwelling radiancr al depth $\mathrm{z}$ : 


$$
\left.\mathrm{dN}\left(\mathbf{z}, \theta_{w}, \Phi_{w}\right)=\sec \theta_{w} \int_{4 \pi} \beta\left(\mathbf{z}, \hat{\bar{\xi}}, \hat{\xi}^{\prime}\right) N_{0}\left(z, \theta_{w}^{\prime}, \phi_{w}^{\prime}\right) \mathrm{d} \Omega, \hat{\xi}^{\prime}\right) \mathrm{d} \mathbf{z}
$$

Let $c(z)$ be the extinction coefficient for single scattering in reciprocal meters as a function of depth. Then we have

$$
N_{0}\left(z, \theta_{w}^{\prime}, \phi_{w}^{\prime}\right)=\operatorname{exf}\left[\sec \theta_{w}^{\prime} \int_{0}^{c} c\left(z^{\prime}\right) d z^{\prime}\right] N_{0}\left(0, \theta_{w}^{\prime}, \phi_{w}^{\prime}\right) d
$$

$\operatorname{ard}$

$$
\mathrm{dN}\left(z, \dot{\theta}_{\mathrm{w}}, \phi_{\mathrm{w}}\right)=\exp \left[\sec \theta_{\mathrm{w}} \int_{0}^{z} \mathrm{c}\left(\mathrm{z}^{\prime}\right) \mathrm{d} \mathrm{z}^{\prime}\right] \mathrm{dN}\left(0, \theta_{w}, \phi_{w}\right) .
$$

We row assume that the depth distribution of optical properties of the sra can be approximated by the assumption of $M$ homogeneous horizontal layers having lower surfice depths of $z_{1}, z_{2}, z_{3}, \ldots, z_{w}$. Substituting (5) and (6) into (4) and using this assumption, the integral over all depths is given by $N\left(0, \theta_{w}, \phi_{w}\right)=\sec \theta_{w} \int_{0}^{2 \pi} \int_{0}^{\pi} \frac{N_{0}\left(0, \theta_{w}^{\prime}, \phi_{w}^{\prime}\right)}{\sec \theta_{w}-\sec \theta_{w}^{\prime}}\left\{\sum_{i=1}^{N} \frac{\beta_{i}\left(\theta_{w}, \phi_{w}, \theta_{w}^{\prime}, \phi_{w}^{\prime}\right)}{c_{i}}\right.$ $\left.\left[e^{\left(\sec \theta_{w}^{\prime}-\sec \theta_{w}\right) \sum_{\substack{i=1 \\ i>1}}^{i-1} c_{j}\left(z_{j}-z_{j}-1^{\prime}\right)}\left[1-e^{\left(\sec \theta_{w}^{\prime}-\sec \theta_{w}\right) c_{i}\left(z_{i}-z_{1}-1\right)}\right]\right]\right\} \sin \theta_{w}^{\prime} d \theta_{w}^{\prime} d \phi_{w}^{\prime}$.

All that remains to complete the model is to replace $N_{0}\left(0, \theta_{w}^{\prime}, \phi_{w}^{\prime}\right)$ in this expreision by the radiances of sunlight and skylight separately. 
In the sun-only case, we assume that $\mathrm{N}_{0}\left(\theta_{w}^{\prime}, \phi_{w}^{\prime}\right)$ is constant over a small solid angle centered around the direction specified by the solar coordinates $\partial_{*}$ and $\Phi_{w}^{0}$ in water. Using this assumption, writing $N_{0}$ in terms of the irradiance $\mathrm{H}_{0}$ due to sunlight incident on a horizontal surface just above the sea, and replacing $N\left(0, \theta_{w}, \phi_{w}\right)$ with the corresponding upwelling radiance $N_{a}^{0}\left(0, \theta_{a}, \phi_{a}\right)$ in air due to the sun only, expression (7) becomes

$$
\begin{aligned}
& \mathbf{N}_{a}^{0}\left(\lambda, \hat{\theta}_{a}, \phi_{a}\right)=\frac{\mathbf{T}\left(\theta_{a}\right) \mathbf{T}\left(\dot{\theta}_{a}^{0}\right) \mathbf{H}_{0}(\lambda)}{\left(\cos \theta_{w}-\cos \theta_{w}^{0}\right) \eta^{2}}\left\{\sum_{i=1}^{4} \frac{\beta_{i}\left(\theta_{w}, \phi_{w}, \forall_{w}^{0}, \phi_{w}^{0}, \lambda\right)}{c_{i}(\lambda)}\right. \\
& {\left[e^{\left(\sec \theta_{w}^{0}-\sec \theta_{w}\right) \sum_{\substack{1=1 \\
i>1}}^{1-1} c_{j}\left(z_{j}-z_{j}-1\right)}\left(1-e^{\left(\sec =e_{w}^{0}-\sec \theta_{w}\right) c_{i}\left(z_{1}-z_{1}-1\right)}\right)\right],}
\end{aligned}
$$

where $\theta_{\mathrm{a}}$ and $\phi_{\mathrm{a}}$ are the look angles and $\varphi_{\mathrm{a}}^{0}$ and $\phi_{\mathrm{a}}^{0}$ are the sus angles in air, measured with respect to the zenith. With this convention, the louk angle $\theta_{a}$ will lie on interval from 0 to $90^{\circ}$. The sun angle $\theta_{a}^{0}$ will lie on the interval from $90^{\circ}$ to $180^{\circ}$. Some simplification results from choosing the cuordinate system 80 that $\phi_{\mathrm{w}}=\ddagger_{\mathrm{w}}^{0}$. In equation (8), T $(\theta)$ is the transmittance for a ray passing into or out of the sea which makes t..e angle $\theta$ in air with the zenith.

In the sky-only case, we assume that $\mathrm{N}_{0}\left(\theta_{w}^{\prime}, \phi_{w}^{\prime}\right)$ in (7) is constant over the full $2 \pi$ sterradians of the sky in air. If $\mathrm{H}_{\mathrm{s}}$ is the skylight irradiance on a horizontal surface just above the ocean, then we can write $N_{0}\left(\theta_{v}^{\prime}, \phi_{w}^{\prime}\right)$ in equation (7) as $\eta^{2} \mathrm{~T}\left(\theta_{\mathrm{a}}^{\prime}\right) \frac{\mathrm{h}_{\mathrm{a}}}{\pi}$, over the angular range from $\theta_{w}^{\prime}=180^{\circ}$ to 


$$
\theta_{w}^{\prime}=\theta_{w}^{c}=-\sin ^{-1}\left(\frac{1}{\eta}\right)
$$

and zero outside that range. $7-j^{c}$ is the critical angle in water. Replacing $N\left(0, \theta_{w}, \Phi_{w}\right)$ on the left hand side of equation (7) by $\left.\frac{n^{2}}{\mathrm{~T}\left(\theta_{a}\right)} N_{e}^{3} ; \theta_{a}, \phi_{a}\right)$, where $\mathrm{N}_{\mathrm{a}}$ is the corresponding upwelling radiance in air due to skylight only, we have

$N_{a}^{s}\left(\lambda, \theta_{a}, \phi_{a}\right)=\frac{T\left(\theta_{a}\right) H_{s}(\lambda)}{\pi \cos \theta_{w}^{\prime}} \int_{0}^{2 \pi} \int_{\pi}^{e_{w}^{c}} \frac{T\left(\theta_{a}^{\prime}\right)}{\sec \theta_{w}-\sec \theta_{w}^{\prime}}\left\{\sum_{i=1}^{M} \frac{\beta_{1}\left(\theta_{w}, \phi_{w}, \theta_{w}^{\prime}, \phi_{w}^{\prime}, \lambda\right)}{c_{i}(\lambda)}\right.$

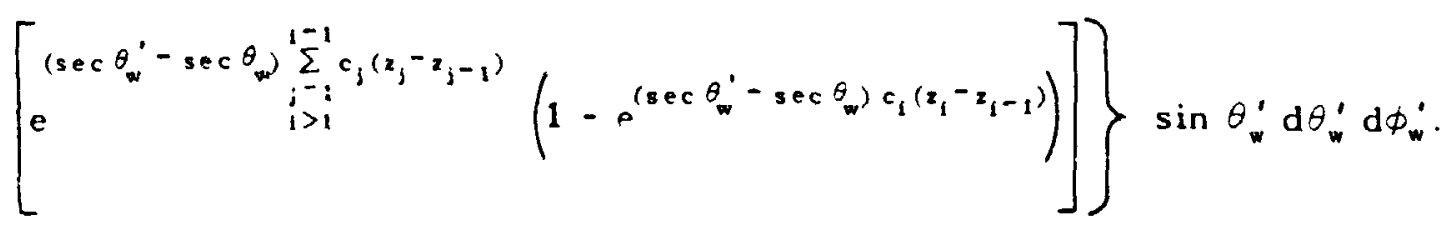

For an infinitely deep, optically homogeneous ocean, equations (8) and (s) reduce to

$$
\mathrm{N}_{\mathrm{a}}^{0}\left(\lambda, \theta_{\mathrm{a}}, \Phi_{\mathrm{a}}\right)=\frac{\mathrm{T}\left(\theta_{\mathrm{a}}\right) \mathrm{T}\left(\theta_{\mathrm{a}}^{0}\right) \mathbf{H}_{0}(\lambda) \beta\left(\lambda, \theta_{w}, \phi_{w}, \theta_{w}^{0}\right)}{\eta^{2} c(\lambda)\left(\cos \theta_{w}-\cos \theta_{w}^{0}\right)}
$$

and 


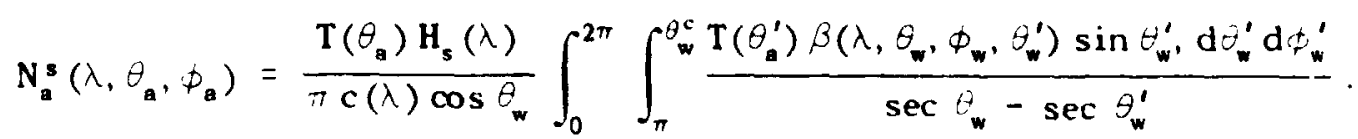

The quasi-single scattering modification to the above relies for its successfulness on the very strong forward scattering exhibited by most natural waters. It is based on the assumption that no downwelling scattered ligtt in the sea is lost from the incident sun and sky light. To implement this assumption, we must first note that the extinction coefficient c can be wiritten as the sum of the a.)sorption coefficient $a$, and the total scattering coefficient $b$, where

$$
b=2 \pi \int_{0}^{\pi} \beta(\gamma) \sin \gamma d \gamma
$$

and $\gamma$ is the scattering angle. We also need to define the forward scattering coefficient

$$
F=\frac{2 \pi}{b} \int_{0}^{\frac{\pi}{2}} \beta(\gamma) \sin \gamma d \gamma
$$

and the backscattering coefficient $B=1-F$. In the quasi-single scattering model the true extinction coefficient for single scattering $\mathbf{c}$ is replaced by $\mathrm{c}^{*}=$ $a+b B=c-F b=c\left(1-\omega_{0} F\right)$ where $\omega_{0}=b / c$ is called the single scattering albedo. Thus, all we have to do to convert our earlier single scattering equations to the quasi-single scattering case is to replace $c$ by $c^{*}$ wherever it appears in those expressions. In particular, the quasi-single scattering versions of equations (10) and (11) are: 


\section{Sun-On!y Case}

$$
\mathbf{N}_{a}^{0}\left(\lambda, \theta_{a}, \phi_{a}\right)=\frac{T\left(\theta_{a}\right) \mathbf{T}\left(\theta_{a}^{0}\right) \mathbf{H}_{0}(\lambda) \beta\left(\lambda, \theta_{w}, \theta_{w}^{0}, \phi_{w}\right)}{\eta^{2}\left(\cos \theta_{w}-\cos \theta_{w}^{0}\right) c(\lambda)\left(1-\omega_{0}(\lambda) \bar{T}(\lambda)\right)}
$$

\section{Sky-Only Case}

$$
\begin{aligned}
& \mathbf{N}_{\mathbf{a}}\left(\lambda, \theta_{\mathbf{a}}, \phi_{\mathbf{a}}\right)=\frac{\mathrm{T}\left(\theta_{\mathbf{a}}\right) \mathbf{H}_{\mathbf{s}}(\lambda)}{\pi \cos \theta_{w} \mathrm{c}(\lambda)\left(1-\omega_{0}(\lambda) \mathbf{F}(\lambda)\right)} \\
& \qquad \int_{0}^{2 \pi} \int_{\pi}^{\theta_{w}^{c}} \frac{\mathrm{T}\left(\theta_{\mathbf{a}}^{\prime}\right) \beta\left(\lambda, \theta_{w}, \phi_{w}, \theta_{w}^{\prime}, \phi_{w}^{\prime}\right) \sin \theta_{w}^{\prime} \mathrm{d} \theta_{w}^{\prime} \mathrm{d} \phi_{w}^{\prime}}{\sec \theta_{w}-\sec \theta_{w}^{\prime}}
\end{aligned}
$$




\section{REFERENCES}

(1) V. Klemas, R. Srna, W. Treasure, and M. Otler, "Applicability of ERTS-1 Imagery to the Study of Suspended Sediment and Aquatic Fronts," Proceedings of the Symposium on Significant Results Obtained from the Earth Resources Technology Satellite-1, NASA, Goddard Space Flight Center, 5-9 March, 1973, edited by Stanley C. Freden, Enrico P. Mercanti, ir d Margaret Becker, pp. 1275-1290.

(2) George A. Maul, "Remote Sensing of Ocean Currents Using ER' " "rery," ibid.

(3) James A. Mueller, "The Influence of Phytoplankton cn Ocean Color Spectra," Ph.D. thesis, Schoul of Oceanography, Oregon State University, Corvallis, Oregon, $1 \mathfrak{3 7 3 .}$

(4) Warren A. Hovis, "Measurements of Ocean Color," Proceedings of a Symposium on the Significant Accomplishments in Sciences, Coddara Space Flight Center, Greenbelt, Md. 20771, 10 November 1971, pp. 24-29.

(5) Benjamin M. Herman, Samual R. Browning, and Zobert J. Curran, "The Effect of Atmospheric Aerosols on Scattered Sunlight," J . Atmos. Sci. 28, 419 (1971).

(6) J. V. Dave, "Intensity and Polarization of the Radiation Emerging from a Plane-Parallel Atmosphere Containing Monntispersed Aerosols," Appl. Opt. $\underline{9}, 2673$ (1970).

(7) Gilbert N. Plass and George W. Kattawar, "Radiative Transfer in an Atmospheric-Ocean System," Appl. Opt. $\underline{8}, 455$ (1969). 
(8) R. E. Turner, W. A. Nalila, and R. F. Nalepka, "importance ot Atmospheric Scattering in Remote Sensing, or Everyshıng You've Always Wanted is. "ow About Atmospheric Scattering but were Afraid to Ask," Proc. $7^{\text {th }}$ [1: Synip. on Rem. Sens. and Environ, Willow Run Laboratories, Institu: ji Sci. and Tech., University w Mıchigan, 1971, pp. 165, 1697.

(9) C. Cox and W. Munk, "Slopes of the Sea Surface Deduce om Photogr"ths of Sun Glitter," Bulletin of _..pps Institution of Oceangrraphy of the University of California, Vol. 6, No. 9, pp. 401-488, U Cal. Press, 1956.

(10) A. E. Strong and I. S. Ruff, "Utilizing Satellite-Observed solar Reflections fiom the Sea Surface as an Indicator of Surface Wind Speeds," Rem. Sensing of Environ. 1 , $181(1970)$.

(1.) Andre Morel, "Diffusion de la lumiere par les eaux de Mer. Resultats experimentaux et approche theorique." Optics of the Sea (Interface and In-Water Transmission and Imaging). AGARD Lecture Series No. 61, North Atlantic Treaty Organization Advisory Group for Aerospace Research

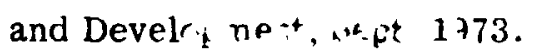

(12) N. G. Teriov, Optical Occ unography (Elsevier Publishing Company, New Yorii) 1968.

(13) N. A. Logan, "A Survey of Some Early Studies of the Scattering of Plane Waves by a Sphere," Proc. IEEE, p. 773, August, 1965.

(14) A. Kerker, The Scatteri.ng of Lighi and Other Electromagnetic Radiation, (Acedemic Press, New York, 1969).

(15) H. R. Gordon and O. B. B own, "Irradiance Reflectivi' $v$ of a Flat Ocean as a Function of its Optical Properties," Appl. Opt. 12, 1549 (1973) 
(16) H.R. Gordon and O. B. Brown, "An Examination of Factors Influencing Ocean Color Usiry Radiative Transfer Theory." Froc. Symr. on Rem. Sens. in Gceanog., 2-5 October 1973, Lake Buena Vista, Fla., Amer. Society of Photogrammetry, Falls Cnurch, Va., 1973 pp. 607-612.

(17) S. Q. Dunt!ey, "Light in the Sea," J. Opt. Soc. Am. 53, 214 (1963).

(18) H. R. Gordon, "A Simple Calculation of the Diffuse Reflectance of the Ocean." to be published in Applied Optics early in 1974.

(19) I. E. Tyler, R. C. Smith, and W. H. Wilson, Jr., "Predicted Optical Properties for "slear Naturai Water," J. Opt. Soc. Am. 62, 83 (1972).

(39) Gunna- Kullenberg, "Scattering of Light by Sargasso Sea Water," Deep Sea Research 15, 423 (1968).

(2!) R. J. Curran, "Ocean Color Determination through a Scattering Atmosphere." Appl. Opt. 8, 1857 (1972).

(22) W. A. Hovis, NASA/GSFC, private communication.

(23) F T. Devis, "Surface Loss of Solar and Sky Radiation by Inland Lakes," Trans. Wisc. Acad. Sci. 33.83 (1941). 


\section{FIGURE CAPTIONS}

Figure 1. Optical processes involved in remote sensing of ocean color.

Figure 2. Upwelling radiance spectra off Santa Catalina obtained by Hovis in 1971.

Figure 3. Subsurface optical model of the sea for remote sensing ocean color

Figure 4. Irradiance reflectivity versus single scattering albedo for three optical models of the sea using phase function A.

Figure 5. Irradiance reflectivity versus single scattering albedo for three optical models of the sea using phase function B.

Figure 6. Irradiance reflectivity versus single scattering albedo for three optical models of the sea using phase function C.

Figure 7. Single scattering albedo spestrum predicted for ciear, natural waters (Tyler, Smith, and Wilson, 1972).

Figure 8. Upwelling radiance spectrum predicted for the Sargasso Sea using two optical models of the sea.

Figure 9. Comparison of theoretical upwelling radiance spectrum for the Sargasso Sea with measurements made by Hovis at an altitude of 305 n: :ters, $250 \mathrm{Km}$ northeast of Cape Hatteras in 1972.

Figure 1G. Scattering model geometry. $z$ - depth of scattering layer of thickness $\mathrm{dz} ; \hat{\bar{\xi}}, \hat{\xi}^{\prime}-$ unit vectors in the directions shown; $d F_{0}, d F_{s}-$ incident and scattered elemental fluxes contained in elemental solid ingles $d \Omega\left(\hat{\xi}^{\prime}\right)$ and $d \Omega(\hat{\xi})$, resp. 


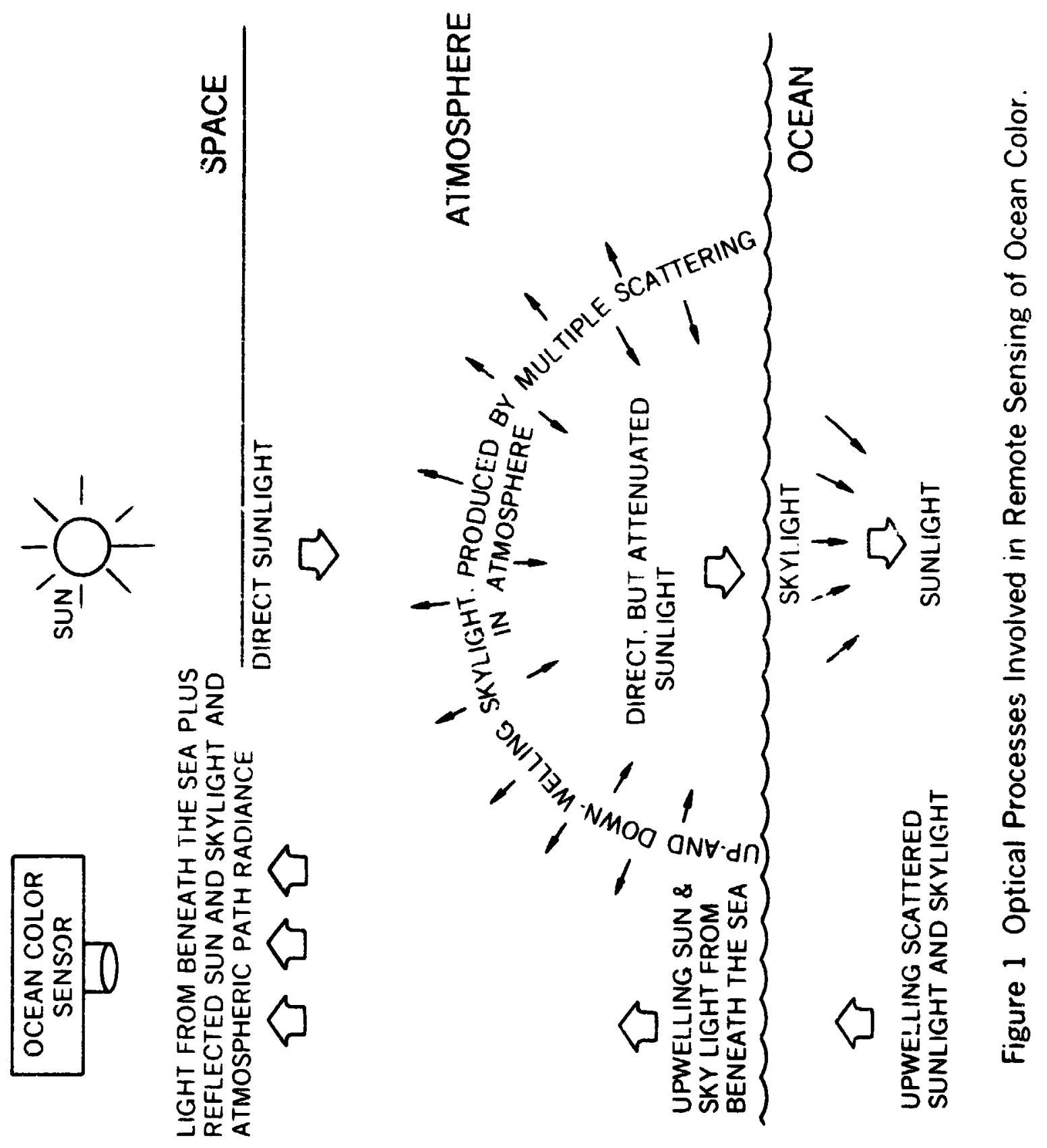




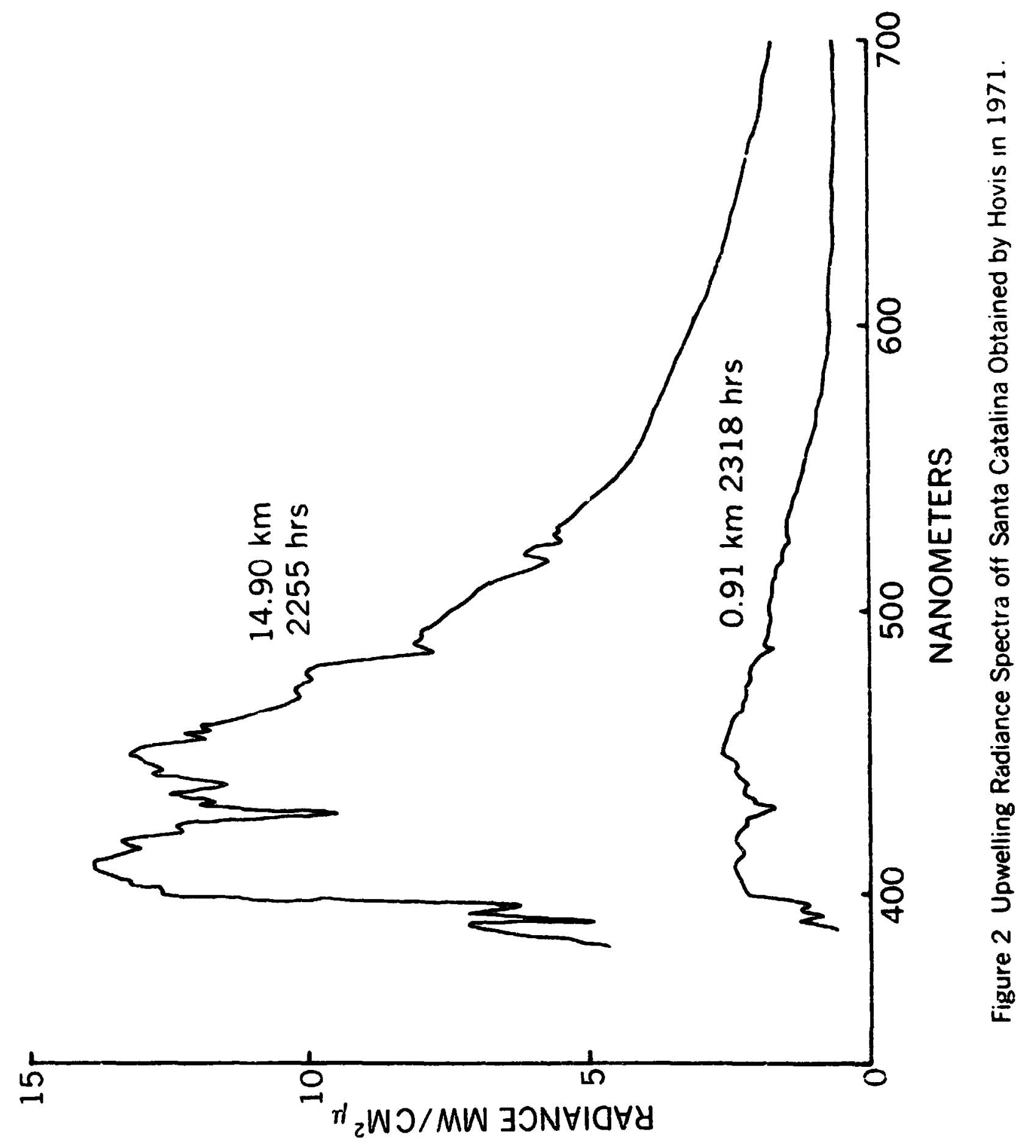




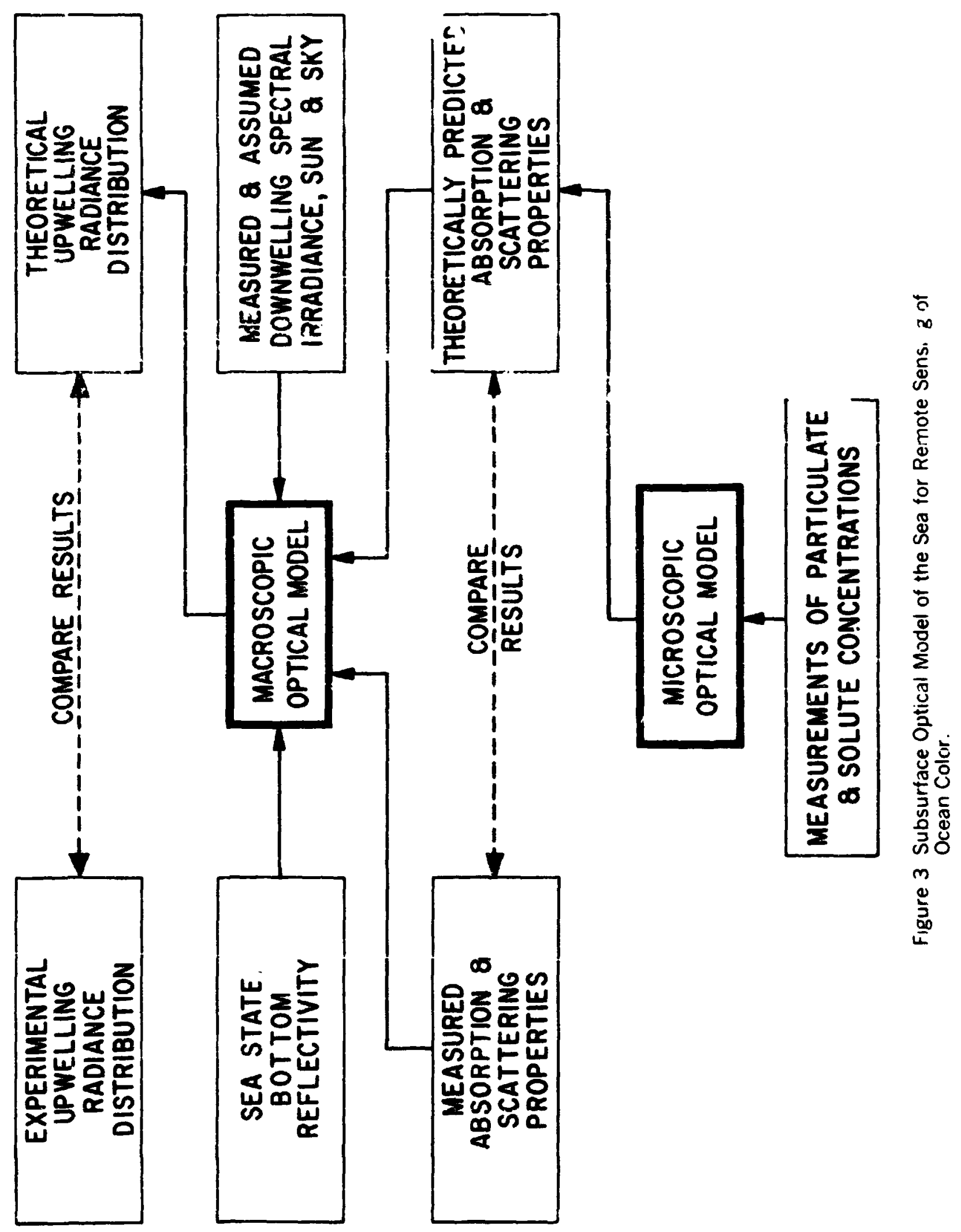




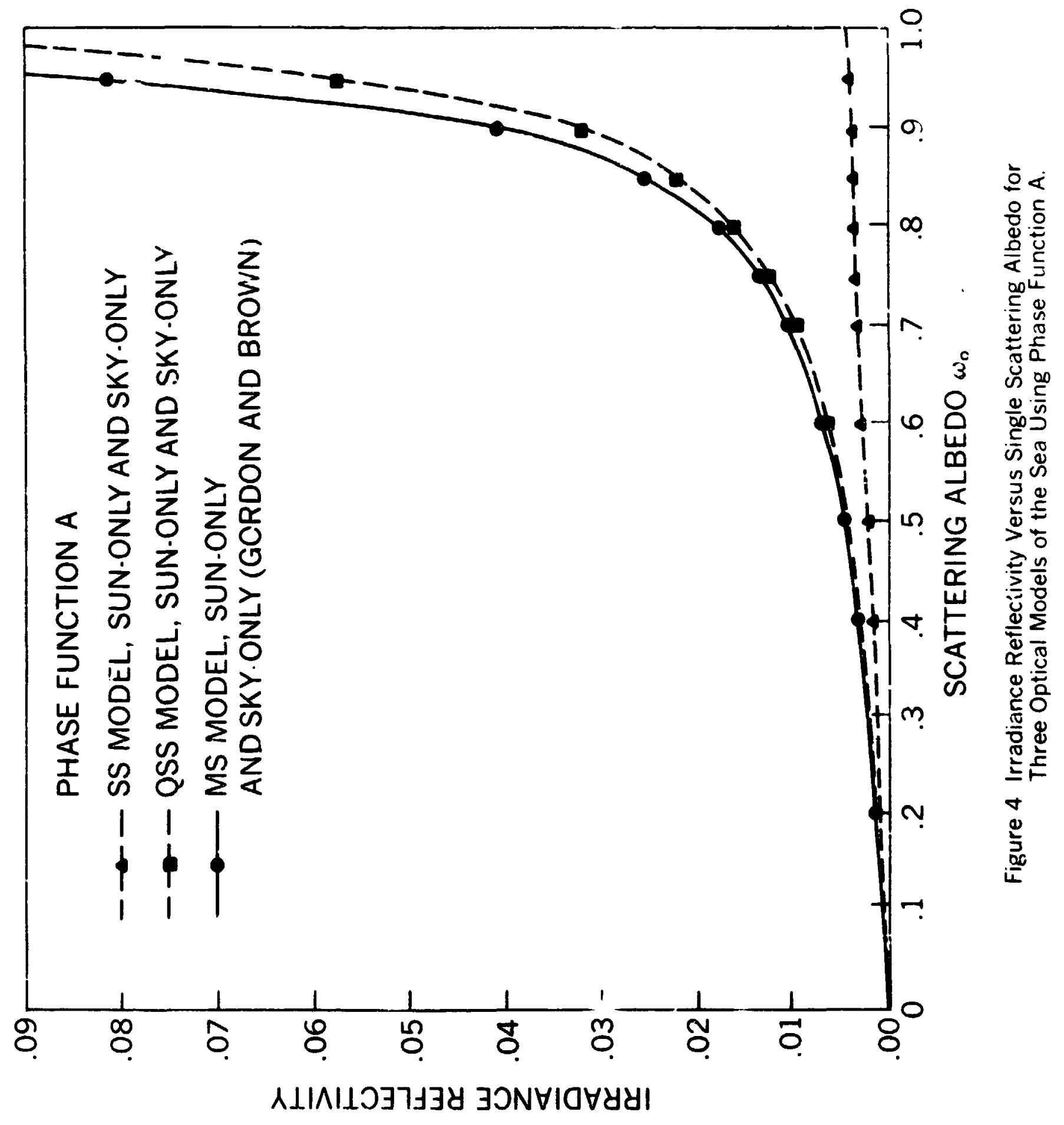




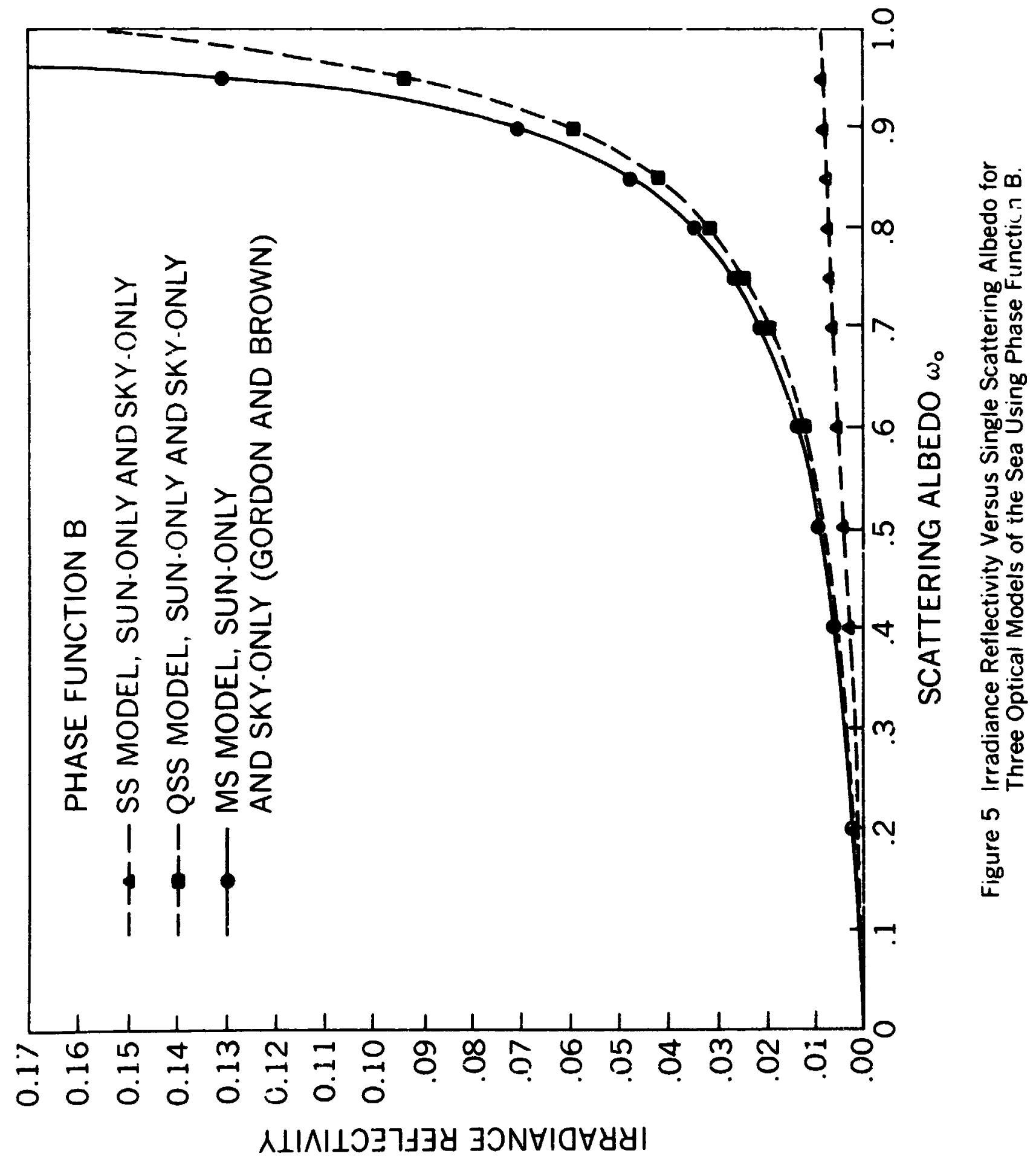




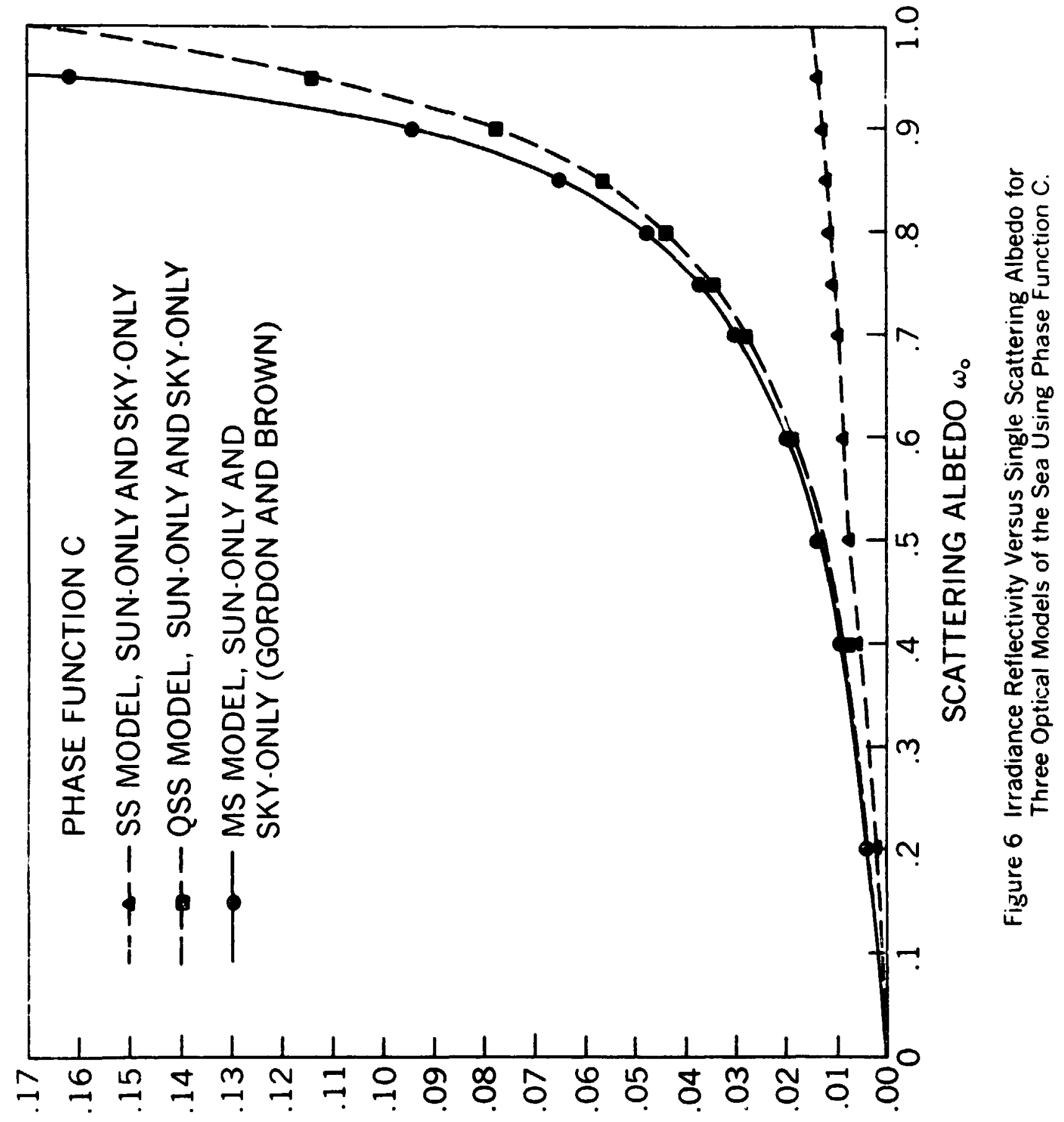

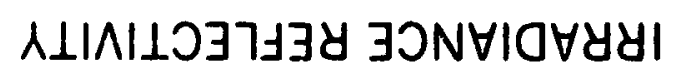




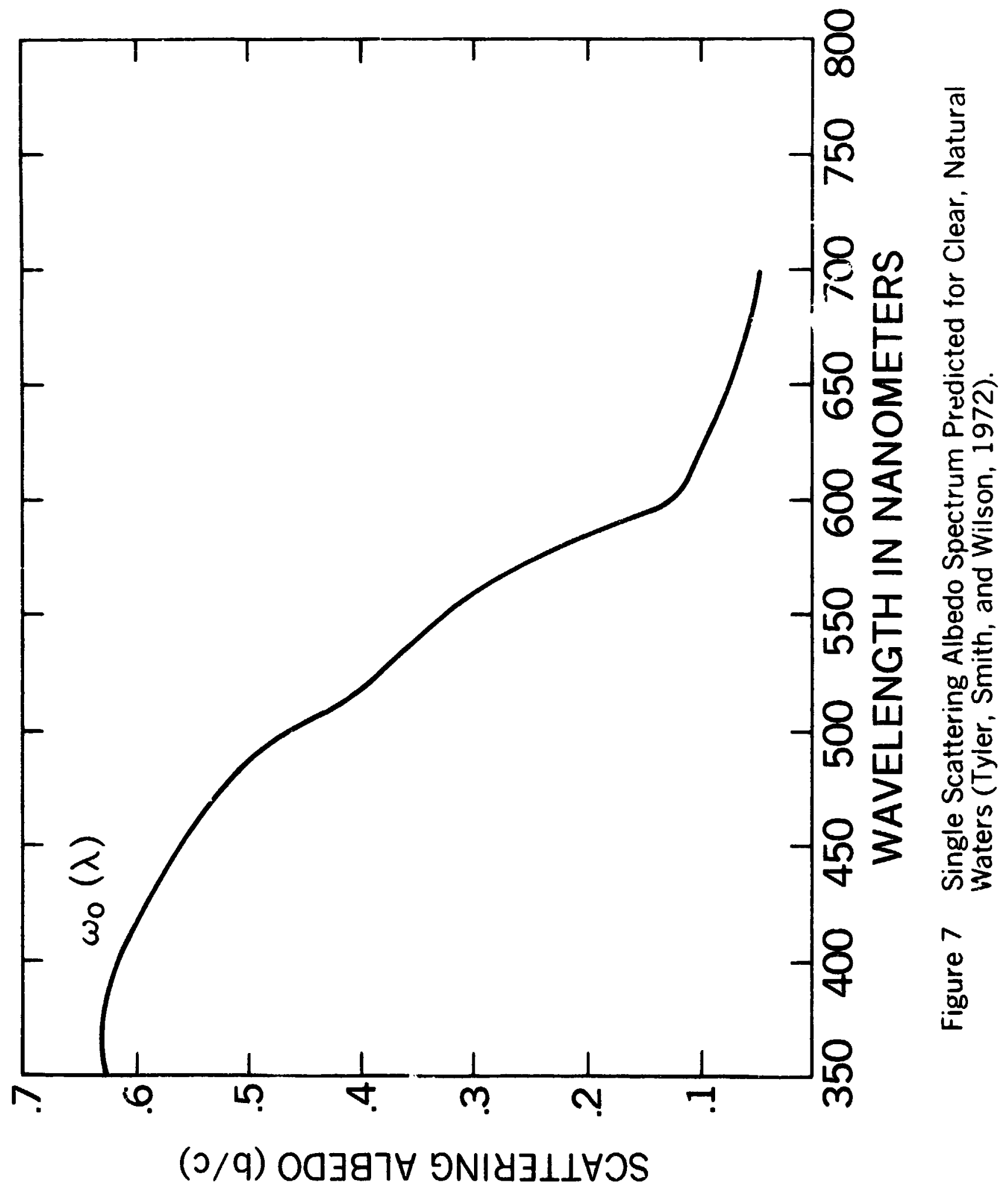




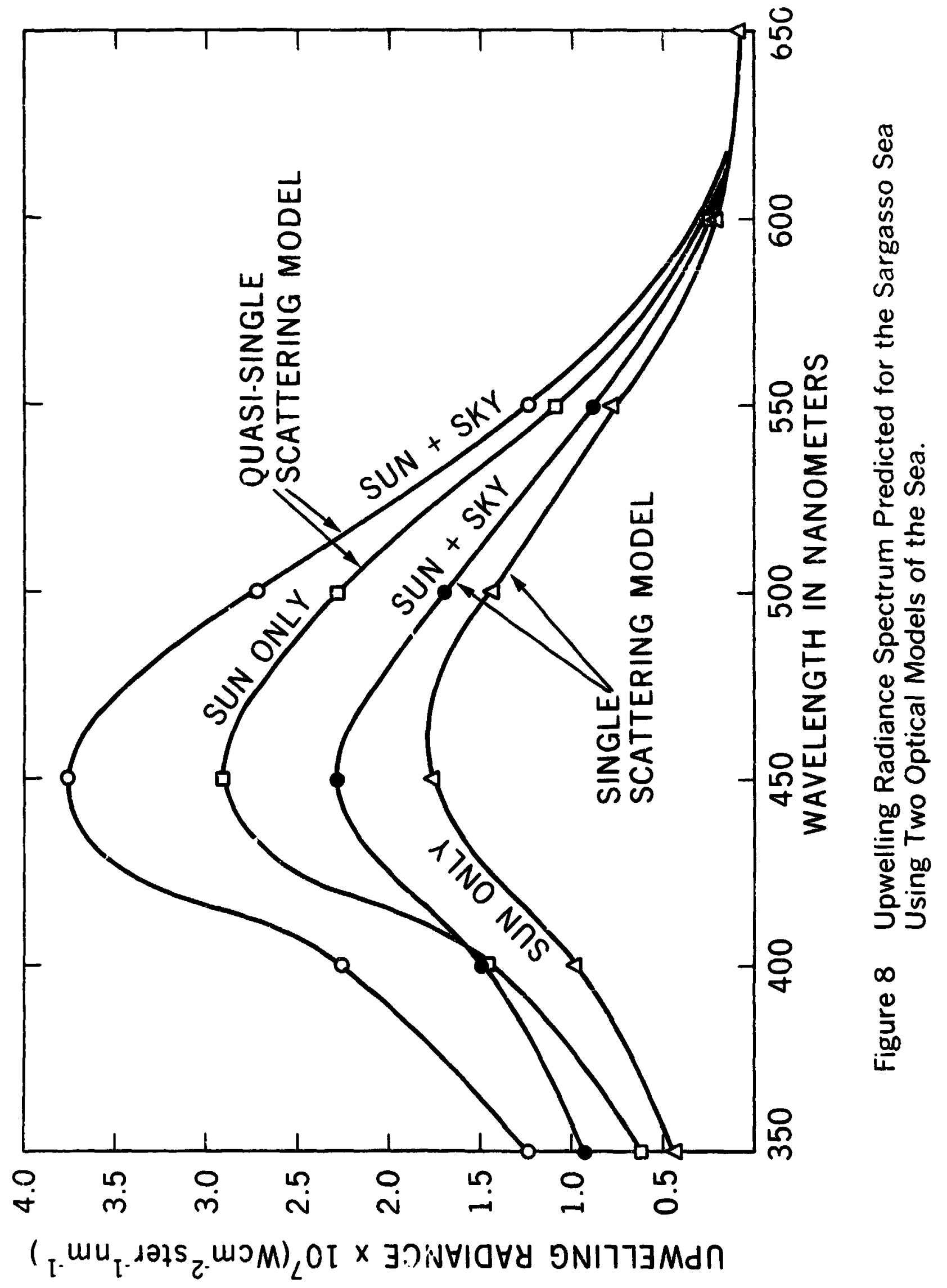




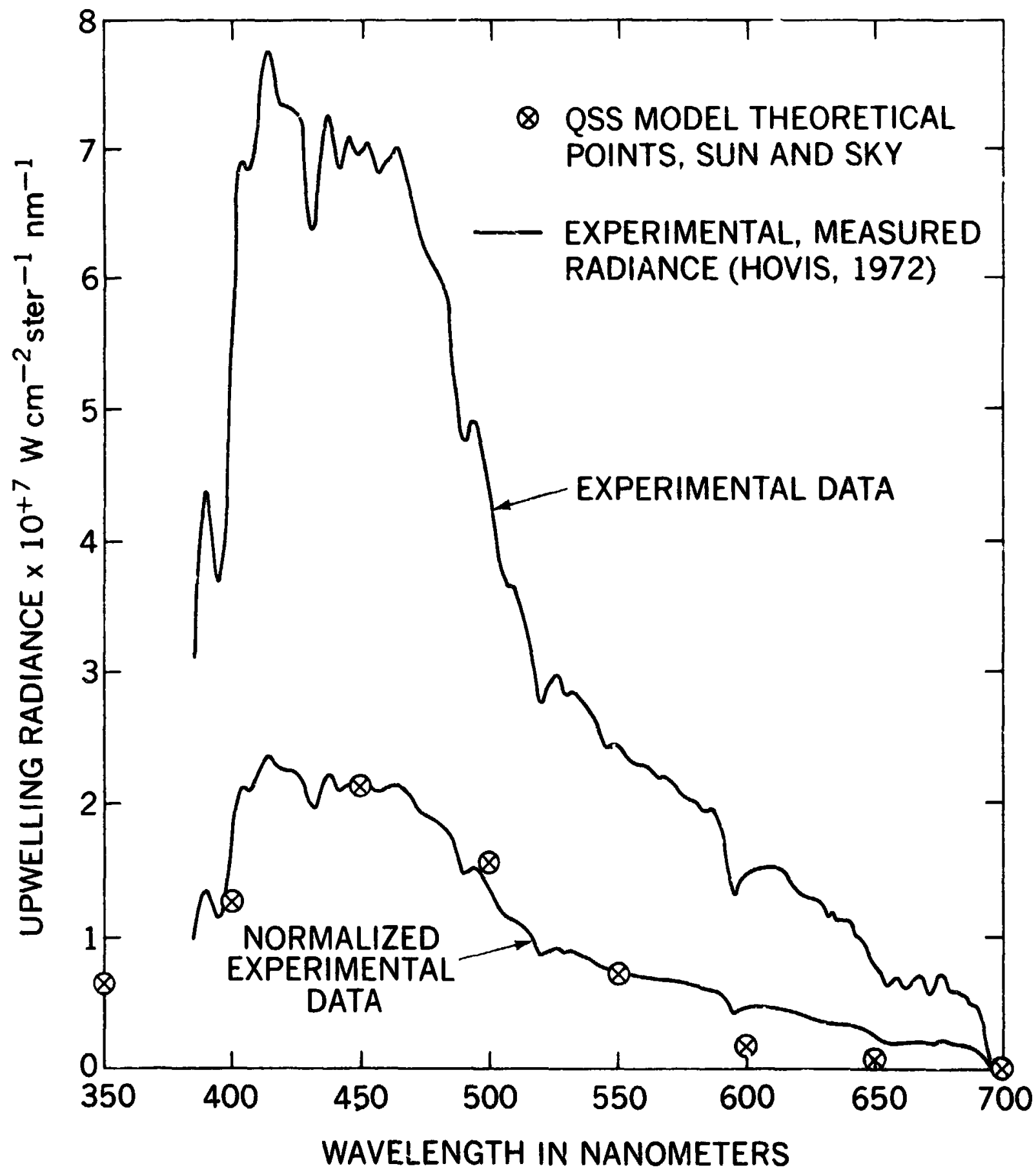

Figure 9. Comparison of Theoretical Upwelling Radiance Spectrum for the Sargasso Sea ( $60^{\circ}$ sun angle) With Measurements Made by Hovis at an Altitude of $1000 \mathrm{ft}$. 150 Miles Northeast of Cape Hatteras in 1972. 


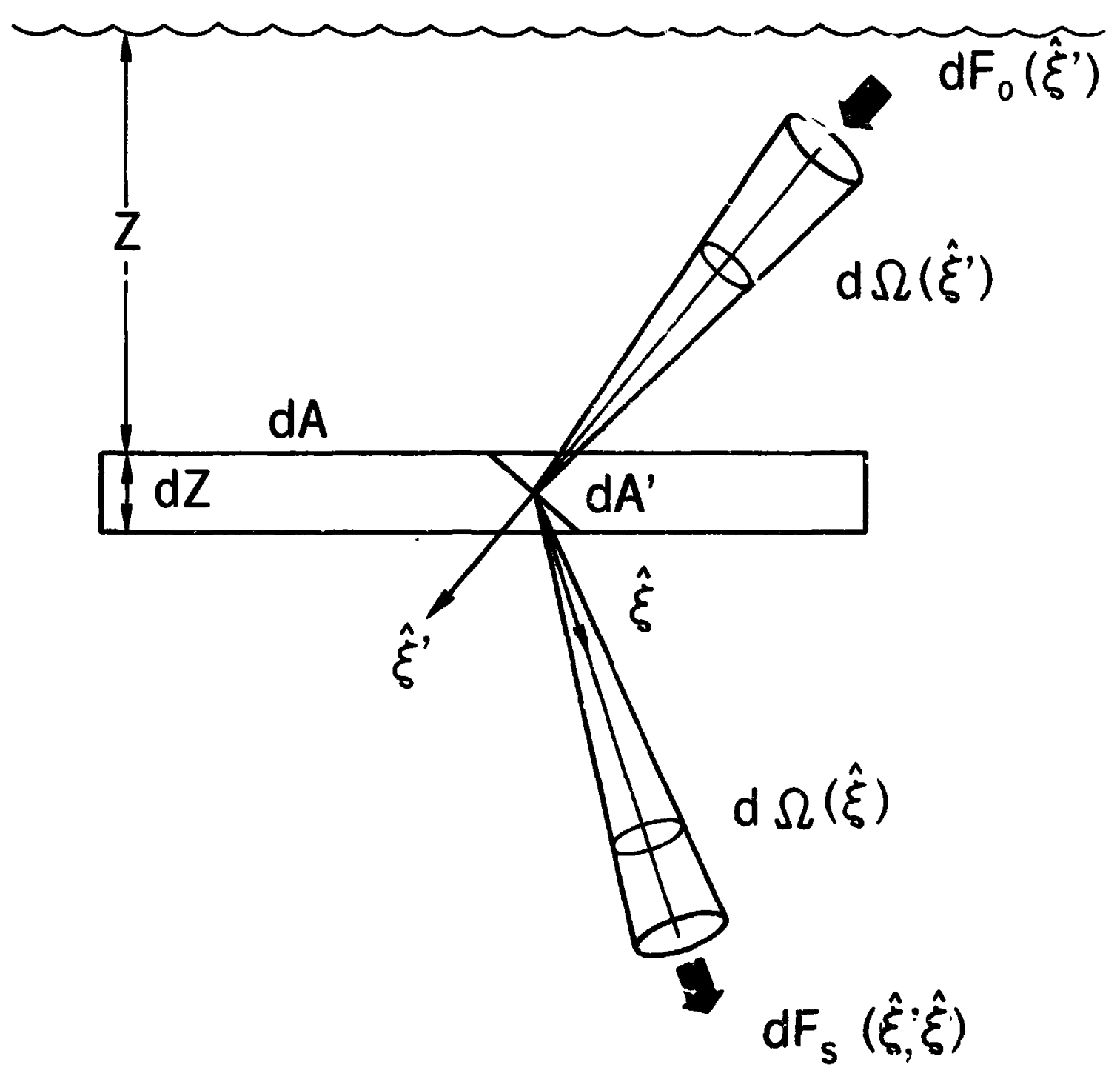

Figure 10 Scattering Mods' Geometry. Z--Depth of Scattering Layer of Thickness $\mathrm{dZ} ; \hat{\xi}, \hat{\xi}^{\prime}$--Unit Vectors in the Directions Shown; $\mathrm{dF}_{0}, \mathrm{dF}_{\mathrm{s}}$ - Incident and Scattered Elemental Fluxes Contained in Elemental Solid Angles $d \Omega\left(\hat{\xi}^{\prime}\right)$ and $d \Omega(\hat{\xi})$. Resp. 